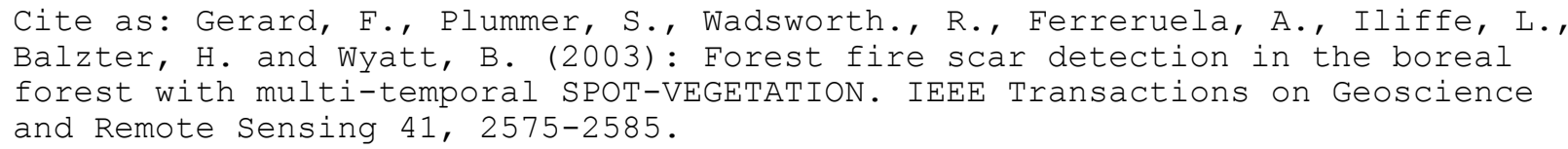

\title{
Forest Fire Scar Detection in the Boreal forest with multi-temporal SPOT-VEGETATION data
}

\author{
F. Gerard, S. Plummer, R. Wadsworth, A. Ferreruela, L. Iliffe, H. Balzter, and B. Wyatt
}

\begin{abstract}
Disturbance events, such as fire, have a major impact on boreal forest dynamics, succession and the global carbon cycle. Methods using satellite imagery are well established for detecting forest fires in real time and mapping the burned area (fire scars) within one year of the fire. This paper focuses on the detection of older fire disturbance-regeneration patterns in the boreal forests of Canada. Previous work found that shortwave-infrared image segmentation proved particularly good at creating uniform regions that were easy to associate with fire scars. Our findings suggest it is possible to detect fire scars up to 10 years old using SPOT VEGETATION data from a single year and that the use of a vegetation index based on near- and shortwave-infrared reflectance is critical to this success. We demonstrate how the use of short term multi-temporal imagery can enhance segmentation results and present a threshold-based procedure for a-posteriori identification of fire scar segments. The resulting fire scar probability map showed a good correspondence with records of fire scars mapped by the Canadian Forest Service for 1980 - 1992 and 'hot spots' from the FireM3 Information System for 1994-1998.
\end{abstract}

Index Terms - forest fire scars, image segmentation, multitemporal remote sensing, shortwave-infrared.

\section{The Role OF Disturbance}

Boreal forests play an important role in the global carbon budget. The boreal forest contains approximately $49 \%$ of the total carbon pool in forested ecosystems [1]; it extends throughout the Northern circumpolar region and covers approximately $10 \%$ of the Earth's land surface. The effects of fire disturbance on this ecosystem are potentially catastrophic, because it is very slow growing, with a short active period,

Manuscript received September, 2002. This work was supported in part by the Natural Environment Research Council and SPOT-VEGETATION Preparatory Programme

F. Gerard, R. Wadsworth, H. Balzter and B. Wyatt are with the NERC Centre for Ecology and Hydrology Monks Wood, Abbots Ripton, PE28 2LS, UK (+44 1487 772400; fax: +44 1487 773467; e-mails: ffg@ceh.ac.uk, rawad@ceh.ac.uk, hbal@ceh.ac.uk, bkw@ceh.ac.uk).

S. Plummer, is with the European Space Agency, European Space Research Institute, Via Galileo Galilei, Casella Postale 64, 00044 Frascati, Italy (e-mail: stephen.plummer@esa.int).

A, Ferreruella, is an MSc student at the University of Leeds typically 120-150 days [2] and subject to nutrient limitation. Further, while the biome contains a high carbon mass, most of this is stored in soil and replacement is limited by temperature and nutrient controls on decomposition [1]. Because forest fires typically release high levels of energy, soil is likely to be combusted.Goulden et al. [3] showed that the carbon losses are not recovered by regrowth, at least in northern boreal forests, where net sequestration into woody biomass is balanced by the release of ancient soil carbon as a direct result of the lowering of the permafrost layer.

There are large annual fluctuations in the area affected by fire; in typical years 5-10 million ha may be burnt [4]; [5]. Examination of decadal averages has shown that $95 \%$ of the area burned is caused by $3 \%$ of fires [6]. Fires also occur in temporal clumps rather than having a consistent average. These clumps are distributed randomly in time, within the fire season, and are associated with weather patterns such as low precipitation and high temperature. Once burned, the disturbance return interval ranges typically from 50 to 240 years, with an average of approximately 100 years [7]. Interannual disturbance rates throughout the boreal system vary widely.

Fire disturbance can have a strong influence on succession in the boreal ecosystem, by creating opportunities for change. For example, crown fires in close succession or extending over large areas may mean the forest in a given area is not able to regenerate due to lack of seed trees and sites for germination. This is evident in Siberia, where areas dominated by lichens can be observed. Pines cannot regenerate without a new ground fire but the fuel load of lichens is too sparse for ground fire to occur so the lichen patches remain [2]. This impoverishment of forests by fire has been suggested as the cause of the belt of treeless areas in the taiga-tundra ecotone in northern Eurasia [8].

Global Circulation Models predict major winter and spring warming in west-central and NW Canada and all of Siberia, with temperature increases of 2-3 degrees. Climate change may alter the frequency and size of disturbance events. Increased fire activity is expected to be an early and significant result of warmer and drier conditions in the boreal zone. It is estimated that fire danger may increase by nearly $50 \%$ and fire 
season length by approximately 30 days if $\mathrm{CO} 2$ concentrations in the atmosphere were to double. This means monitoring changes in the spatial distribution, area and temporal occurrence of fires is vital for predicting the impacts of global environmental change [9].

\section{DATA REQUiREMENTS}

Reliable estimates of the return periods, size and recovery rate of fire disturbance ideally require time-series of spatiallyreferenced data for boreal forest over a period of at least a hundred years. Such data are not available from any source, so reliance must be placed on short timescale but spatially comprehensive information (e.g. GLOBSCAR, a global fire scar product derived from Earth observation [10]), long timescale but site-specific data (e.g. dendrochronology) or modeling.

\section{A. Databases}

Currently, there is no comprehensive spatial database of disturbance across the entire boreal ecosystem. Where efforts to collate information have been attempted, these are usually either spatially restricted or a snapshot in time. The standard methods of fire observation are individual wildfire reports prepared by forest fire management agencies [11]; [12]. In Canada, wildfire reports typically comprise data on fire number, location (point of ignition), size and start and end dates. The area burned is derived either from aerial sketch maps or a posteriori aerial photographic interpretation. This can be supplemented by information on fire type and severity, derived indirectly from height of burn-marks on stems, fire spread rate, flame height, level of combusted litter or mortality of trees. These indicators are used to define a particular fire type (ground, crown) and three intensity levels - low, medium and high. However, such reporting is rarely comprehensive; for example, approximately $40 \%$ of the Russian forest does not receive fire protection or monitoring [8].

In Canada, a major initiative was started to co-ordinate, compile and rationalise wildfire reports from different provinces into a comprehensive annual database focusing on those fires greater than 200 ha. These fires represent $98 \%$ of the total area burned. The Canadian Large Fire Database (LFDB), co-ordinated by the Canadian Forest Service, is a systematic compilation that records all fires larger then 200 ha.

(http://www.nofc.forestry.ca/fire/frn/English/ClimateChange/L FDB8095.htm). The dataset includes digitised and georeferenced maps of final fire perimeters. The original goal was to build a database for the country from 1980 to present, as from this date, record keeping and large fire perimeter mapping were quite complete throughout Canada. The LFDB is now being backdated to include the full archive from each of the provinces and territories.

\section{B. Earth Observation}

Earth observation offers the most appropriate spatial and within-year temporal resolution. However, the longest global record extends from only 1981 to the present, in the form of AVHRR imagery from the NOAA satellite series. Data from this source are widely available at spatial resolutions of $1 \mathrm{~km}$, $4 \mathrm{~km}$ and $8 \mathrm{~km}$ and temporal resolutions varying typically from daily coverage to 10 - or 18-day composites. The thermal data of the AVHRR sensors have been used for locating fires in real time, i.e. fire hot spots [13]; [14]; the optical data for (i) estimating burned area one month to one year after the fire has occurred, i.e. recent fire scars [15-18] and a combination of both for monitoring wildfire evolution [19]. Similarly, thermal and optical data from more recent coarse-scale sensors are being used for hot spot detection (ATSR series: [20] and MODIS: [21] and for recent fire scar mapping (ATSR series: [22], [23] and SPOT-VEGETATION: [24] respectively. At higher spatial resolution, the optical sensor, Landsat TM, has been used to map burned areas and fire severity [25], [26]; [27] and the active microwave sensor, ERS-1 SAR, to separate burned areas into damage classes [28].

Hotspot detection relies on the difference between the heat of the observed fires and the relatively cold surroundings. The main algorithms that have been developed are either thresholdbased methods or contextual methods. A thorough review of hot spot detection algorithms is presented in [29]. A number of tests are normally required to remove false alarms caused, in particular, by sun glint, warm backgrounds, industry, cloud reflection and bright-scene objects. To date, a number of national and global active fire products derived from EO are available online (e.g. ATSR world fire atlas website: shark1.esrin.esa.it/ionia/FIRE/, World Fire Web website: www.gvm.sai.jrc.it/fire/default.htm, MODIS Land Rapid Response system website: firemaps.geog.umd.edu/). Hotspot products are obtainable from 1992, 1993 and 1995 to the present on a daily, 8-10 daily or monthly basis. The accuracy of fire detection from these products is low for fires of low intensity (e.g. ground fires, fires in the taiga) and can be hampered by false alarms and cloud cover.

Fire scar mapping using optical imagery exploits the differences observed in the spectral signatures between healthy forest canopy and forests destroyed or damaged by fire. Healthy green vegetation, including forests, typically absorbs light in the red $(0.6 \mu \mathrm{m}-0.7 \mu \mathrm{m})$ wavelengths (chlorophyll absorption), scatters light in the near infrared (NIR: $0.7 \mu \mathrm{m}-$ $1.3 \mu \mathrm{m}$ ) (intra cellular scattering) and absorbs in the shortwave-infrared (SWIR: $1.4 \mu \mathrm{m}-1.8 \mu \mathrm{m}$ ) (plant moisture absorption). After burning, more soil is exposed and the whole or proportions of the forest will have been destroyed. This generally results in a spectral signature showing higher red, lower NIR and higher SWIR reflectance values, although charcoal on the surface can temporarily lower the red signal. Methods developed for optical imagery [15, 17, 22, 30-32], [13] include:

- Normalised Difference Vegetation Index (NDVI) differencing (e.g. [13]).

- Thresholding of single bands (e.g. [25] [31]). 
- Thresholding of multiple bands and vegetation indices (e.g. [17, 23, 33])

- Unsupervised image classification (e.g. [15], [34], [31]

- Image segmentation (e.g. [31])

Most of the methods listed produce reasonable results for estimating the extent of burned areas in the year that the fire occurred. The majority of the most successful methods used thresholding of a combination of bands and usually included brightness temperature. Those of [33] and [23] showed greatest promise when tested against other approaches [35]. An algorithm that exploits features of the two approaches has been adopted for the production of GLOBSCAR, a global burned area product derived from ATSR-2 imagery [10].

GLOBSCAR is available from the European Space Agency. It shows monthly burned areas at $1 \mathrm{~km}$ resolution for the year 2000 (web site $=$ www.geosuccess.net). The Joint Research Centre at Ispra (Italy) has also produced a $1 \mathrm{~km}$ global map of burnt areas for the year 2000 (GBA2000) from daily SPOTVEGETATION imagery (www.gvm.sai.jrc.it/fire/gba2000 _website/gba2000_data.htm). Unlike GLOBSCAR, which applies two fire scar detection algorithms in tandem, GBA2000 implements algorithms developed independently for the different biomes and continents.

With respect to the large area monitoring of older fire scars (i.e. areas burned more than one year prior to image acquisition) and their regeneration patterns, Earth observation tools are not well developed [34]. Nevertheless, [31] and [24] have shown that the shortwave-infrared band is critical to the detection of older forest fire scars. Canopy moisture content, to which SWIR is sensitive, may be linked to vegetation type and canopy structure. This may explain why, in the SWIR, older regenerating fire scars are distinguishable from the surrounding mature forests. [31] tested thresholding, unsupervised classification and image segmentation on Landsat TM and simulated SPOT-VEGETATION data for mapping older fire scars in the Canadian boreal forest. Although the segmentation approach is more computerintensive than unsupervised classification, it proved particularly good at selecting uniform regions in the SWIR, which were easy to associate with data from the Canadian Large Fire Database (LFDB). The main problem with the segmentation approach is that it relies on an a-posteriori identification of the fire scar segments.

In the following sections, we present results that concern the detection of older fire scars in the boreal forest of Canada and extend the segmentation work of [31]. We propose a solution to the a-posteriori identification of fire scar segments and demonstrate how the use of short-term multi-temporal imagery can enhance segmentation results.

\section{DATA ACQUISITION AND METHODS}

\section{A. Fire Information}

Records of fire scars between $1980-1992$ for a $6^{\circ} \times 4^{\circ}$ area in Canada, centred on latitude $56.5^{\circ} \mathrm{N}$, Longitude $99^{\circ} \mathrm{W}$, were provided by the Canadian Forest Service and the active fire detections generated by the FireM3 system were made available by the Canadian Centre for Remote Sensing (CCRS). FireM3 identifies active fires from four daily afternoon passes across Canada by NOAA/AVHRR. The AVHRR fire detection algorithm used in FireM3 [14, 36] was developed and tested specifically for boreal forest fires. Both datasets were imported into Arc/Info and re-projected into the same reference system as the SPOT-VEGETATION data. Each fire year was recorded as a distinct layer in Arc/Info.

\section{B. SPOT-VEGETATION data}

The overall study area stretches from Hudson Bay in the east to Saskatchewan in the west (Latitude range: 57 to $51^{\circ} \mathrm{N}$, Longitude range: 116 to $\left.76^{\circ} \mathrm{W}\right)$. A total of 25 SPOTVEGETATION-P1 images were acquired (Table I). The P1 image product includes geo-referencing and conversion to top of atmosphere reflectance. Of the 25 images, the 17 least cloudy (shaded) were used in subsequent analysis. The 17 images do not cover the same geographical extent so that the number of image layers available varies spatially across the overall study area. The method was first developed on a subset of $700 * 700 \mathrm{~km}$ (Lat. Range: 56.5 to $53.5^{\circ} \mathrm{N}$, Long. Range: 103 to $97^{\circ} \mathrm{W}$ ) and was then implemented for the complete area. The subset has 17 images.

\section{TABLE I}

SPOT-VEGETATION images acquired for study; the images used for analysis are shaded in grey.

\begin{tabular}{lllll}
\hline \hline May & June & July & August & September \\
\hline $98-05-21$ & $98-06-06$ & $98-07-02$ & $98-08-21$ & $98-10-01$ \\
$98-05-22$ & $98-06-07$ & $98-07-30$ & $98-08-21$ & $98-10-02$ \\
$98-05-23$ & $98-06-21$ & $98-07-31$ & $98-08-29$ & $98-10-02$ \\
$98-05-25$ & $98-06-23$ & $98-08-03$ & $98-08-30$ & $98-10-03$ \\
& $98-06-29$ & & $98-09-05$ & $98-10-03$ \\
& & & & $98-10-04$ \\
& & & & $98-10-07$ \\
\hline \hline
\end{tabular}

\section{Pre-processing}

The SMAC-v2.0 [37] atmospheric correction scheme was applied to the data to derive surface reflectance values, using atmospheric and geometric reference data supplied with the imagery. - Correction to surface reflectance was a prerequisite, to allow assessment of the reflectance characteristics of fire scars in terms of phenology and age. The effect of varying view angles was limited by restricting the image analysis to the image subset approximately centered in the middle of the full image. Cloud and water masks were created for each image, using image specific band- and NDVIthresholding.

\section{Image segmentation}

As the SWIR was known to be critical for the detection of older fire scars, segmentations were carried out on the individual SWIR waveband and NDSWIR, an index, that 
exploits NIR and SWIR. These were compared with segmentations derived from comparable NDVI images:

NDVI: $\frac{\rho_{N I R}-\rho_{R E D}}{\rho_{N I R}+\rho_{R E D}}$

NDSWIR: $\frac{\rho_{N I R}-\rho_{S W I R}}{\rho_{N I R}+\rho_{S W I R}}$

The segmentation procedure applied was a 'region-merging' segmentation algorithm [38] provided by the CAESAR software (webpage: http://www.nasoftware.co.uk/sar/). The MUM segmentation procedure "grows" segments by merging neighbouring patches starting from random seedpoints. The decision to merge depends on the statistical criterion adopted. For each pair of adjacent regions, MUM calculates the likelihood that they arise from the same underlying population. It then chooses the most similar regions and merges them. This process is repeated until the likelihood of similarity falls below a probability 'threshold' set by the user. CAESAR was originally developed for SAR data and requires a 'number-oflooks' parameter to be set, this specifies how much of the local spatial variability is to be considered as noise rather than information. The optimisation of these input values is not trivial, as a similar number of segments can be achieved with different combinations of 'threshold' and 'number-of-looks' (Fig. 1). In each case, the segments obey the same statistical criteria and are therefore equally valid realisations. Segmentation results also depend on:

- the spatial and spectral characteristics of the input image, and

- the algorithms used by the segmentation procedure.

The optimisation of the input parameters was achieved by assessing the size distribution of the LFDB fire scars against the resulting segment size distributions. We found that segmentations that produced a segment size distribution matching closely the shape of the LFDB size distribution, gave the highest degree of correspondence between individual segments and LFDB polygons. The optimal 'threshold' and 'number-of-looks' used subsequently for the segmentation of both the subset area and the full area are 0.000001 and 25 respectively.

\section{E. Fire scar probability map}

Segmentation results from individual images vary with image quality and season. However, it is assumed that segmentation is consistent across images for constant and spectrally distinct features such as fire scars and lakes. The fire scar probability map is based on the cumulative co-location of such individual image segments. In general, it is reasonable to expect that this output is likely to be an improvement on the results of individual image segmentation. The key steps involved in the creation of the fire probability map are (Fig. 2):

- segmentation applied to one year multi-temporal image set (spring to autumn);

- a posteriori identification of fire scar segments;
- calculation of per-pixel fire scar probability $\mathrm{P}_{\text {firescar }}$ based on the frequency of a pixel belonging to an image segment being identified as a fire scar.

This method depends critically on the a posteriori identification of segments as fire scars. With the initial test area $(700 \mathrm{~km} \mathrm{x} 700 \mathrm{~km})$, the LFDB fire map and the FireM3 hotspots could be used to identify the fire scar segments and produce a temporary probability map as follows [39]:

$P_{\text {firescar }}=\frac{N_{\text {firescar }}}{N_{\text {image }}-N_{\text {rejected }}}$

Where

$\mathrm{N}_{\text {firescar }}$ : number of times the image pixel belongs to a segment that shows a $15 \%$ overlap with a LFDB fire map polygon or includes at least one FireM3 hotspot.

$\mathrm{N}_{\text {image }}$ : total number of images in cumulative image set

$\mathrm{N}_{\text {rejected }}$ : number of times the image pixel is tagged as cloud, water, or no-data.

This temporary probability map was used to extract candidate 'fire scar' pixels from individual images and thus provided a means of investigating a posteriori assignment mechanisms based on reflectance.

\section{RESUlTS}

\section{A. Image segmentation}

Segmentations of SWIR, NDVI, and NDSWIR were compared with the LFDB fire scar polygons and the FireM3 fire hotspot points. Fig. 3 shows the original SWIR, NDVI and NDSWIR vegetation indices and resulting segmentations produced from the SPOT-VEGETATION image of 29 June 1998. Fire scar vectors for 1989 from the LFDB are shown for comparison. The known fire scars exhibited consistently low values in NDSWIR and high values in SWIR but exhibited no unique or consistent separation in NDVI. The match with the reference fire data was consistently better for segmentations of NDSWIR than for segmentations of the SWIR image or NDVI. In addition, the NDSWIR segmentations seemed to be less influenced by water, haze or thin cloud. Qualitative comparison against LFDB data for 1989 reveals fire scars to be consistently dark in all images. However, not all scars are selected in all images. Also evident were multiple segments within what LFDB treats as single-event fire scars. In combination, these segments fit within the fire scar but these could be indicative of possible differences in fire severity or re-growth and could affect attempts at applying uniform thresholds. The next section investigates whether the reflectance characteristics of the fire scars could be used to assign segments a posteriori.

\section{B. Spectral Behaviour of fire Scars: individual fire years.}

Average values of reflectances, NDVI and NDSWIR for segments that returned a fire scar probability of more than $80 \%$ (Fig. 4). were compared with average values from forest regions where no fire had been recorded, i.e. pixels with a fire scar probability of less than $10 \%$. 
A first step was to see how the average reflectance, NDVI and NDSWIR values of all areas burned in the same year compare with 'recovery' or fire scar age. Fig. 4 shows the average NDVI and NDSWIR values calculated for scars of the same fire year, from three separate images (May, June and October). For NDVI, the average scar values are considerably closer to the value for surrounding forest and there are overlaps at the first standard deviation, particularly during the peak growth period (June/July). By contrast, the average NDSWIR scar values are clearly separated from the surrounding non-burned in all images beyond the level of the first standard deviation. The separation is clearer in early and late season (May and October).

Note, that these mean and standard deviation values are affected by the population of scar pixels per fire year, hence there are no data for fire years 1982-1986 and 1992-93, when fire scars were either not present in the study area or could not be detected by the preliminary probability map. The apparent anomaly in 1988 may be due to the small area burnt (only 89 $\mathrm{km}^{2}$ ) compared to 1989 when $33,430 \mathrm{~km}^{2}$ burnt. In addition, while every effort was taken to avoid cloud pixels in the calculation, using the cloud mask, some values may have been included and, for NDSWIR, these may have an adverse effect since cloud is very bright while scars are dark. Both the scar averages of NDVI and NDSWIR exhibit a consistent nearlinear trend in signal from low values for fire year 1996 increasing towards the surrounding unburned values for 1980 . In 1997 there were few fires in the region, hence the large standard deviation around the mean.

Fig. 5 shows the average signal variation over the active growth cycle, from May to September 1998, as extracted from the multi-temporal imagery, for the NDSWIR for areas burned in 1981 and 1989. The NDSWIR is generally lower compared to the 'unburned' forest and shows better separation in spring and autumn. Separation is clearer for 1989 than 1981, although the scatter about the average still causes considerable overlap between fire scars in one image (e.g. Aug.) and the non-scar in the next image (e.g. Sept.). This suggests that the use of a NDSWIR threshold for a posteriori scar identification on a multi-temporal set of segmented images would be possible only if image-specific threshold values are used.

\section{Spectral Behaviour of Fire Scars: individual scars.}

The previous section considered the combined average spectral behaviour of all forest areas burned in a given year. This presumes that the conditions for each fire and the severity of the fire were the same. Given observations that the controls over fire spread and intensity are climate, fuel amount and condition and topography this represents an oversimplification. It has already been observed that LFDB fire polygons are sometimes correspond to multiple segments. Future work must examine the NDSWIR signals of fire scar and their sub-scar segments to determine if these can be used to indicate faster or slower than average recovery or some indication of severity.

\section{A posteriori segment labeling procedure and resulting fire scar probability maps}

Examination of reflectance, NDVI and NDSWIR showed a closer association of the NDSWIR with fire scars of varying age. Generally the pixels within fire scar segments have lower NDSWIR values compared with the non-burned segments. Their separation therefore might be possible by means of an image specific (i.e. adaptive) NDSWIR threshold. Histograms of the mean NDSWIR values of segments from the $700 \mathrm{~km} \mathrm{x}$ $700 \mathrm{~km}$ subset area of single SPOT-VEGETATION images revealed distinct bimodal distributions, reflecting the burnt and unburnt areas (Fig. 6). In this case, optimal thresholds could be established to separate the two populations by maximising the standard student- $\mathrm{T}$ statistic used to compare the two populations (Fig. 6). We subsequently used this threshold value in an a posteriori labeling procedure to subdivide the original unsegmented NDSWIR imagery into fire scar pixels and non-fire scar pixels. The method then combined the resulting binary image with the respective segmented images to calculate, for each segment, the percentage of pixels that tested positive for fire scar. This percentage value was assigned to all pixels of a given segment. The fire scar probability $\mathrm{P}_{\text {firescar }}$ is then calculated as follows:

$P_{\text {firescar }}=\frac{\sum_{i=1}^{N_{i m g}-N_{r i j}} X_{i}}{N_{\text {img }}-N_{\text {rej }}}$

where:

$\mathrm{X}_{\mathrm{i}}: N_{\text {burt }} / N_{\text {seg }}$ for the segment of image $i$ to which pixel belongs.

$\mathrm{N}_{\text {img }} \quad$ : total number of images in cumulative image set.

$\mathrm{N}_{\mathrm{rej}}$ : number of times the image pixel is tagged as cloud, water, or no-data.

For this approach to work, it is important to exclude all image pixels outside the forested area (e.g. arable land, wetland, grassland, water) from the histogram and to apply cloud masks prior to image segmentation. The IGBP global land cover map produced from AVHRR imagery (http://edcdaac.usgs.gov/glcc/glcc.html) was used to separate the main forested areas from other cover types.

1) Fire probability map for the subset area

Fig. 7 a shows the resulting fire probability map for the subset area, created from 17 SPOT VEGETATION images. The grey and black areas have a probability of $50 \%$ to $75 \%$ and $75 \%$ to $90 \%$ respectively. When comparing the areas with a $50 \%$ fire scar probability or more with the combined LFDB-FireM3 reference data (Fig. 7b) the correspondence is high: $89.76 \%$ with Kappa of 0.64 (Table II). The probability map identifies a total of $85,512 \mathrm{~km}^{2}$ of burnt area whilst the combined LFDBFireM3 reference data gives a total of 70,194 km². Fig 7c. supports this: the scars on the probability map show a good correspondence with the polygons or have FireM3 hotspots within their boundary or nearby. In a very few cases $(4 \%$ omission), however, it is not possible to associate LFDB polygons or FireM3 hotspot clusters with a scar on the probability map, i.e. the scar is not detected. Without additional auxiliary information it is difficult to know the cause of this, but a likely explanation may be that the size or the intensity of these fires was too small for the resulting scars to become visible at $1 \mathrm{~km}$ spatial resolution. More often $(8 \%$ 
commission) areas are identified as fire scars which according to the combined LFDB-FireM3 reference data were not burnt. These commission errors are often associated with areas near hotspot clusters which would suggest that the probability map identified an actual burn.

TABLE II

Correspondence matrix (\%) between the fire probability map and the combined LFDB-FireM3 reference data for an area of $454,960 \mathrm{~km}^{2}$.

\begin{tabular}{|c|c|c|c|c|c|}
\hline & \multicolumn{5}{|c|}{ Areas with $>50 \%$ fire scar probability } \\
\hline & Areas with $>$ & fire & $\begin{array}{l}\text { non- } \\
\text { fire }\end{array}$ & $\begin{array}{l}\text { row } \\
\text { total }\end{array}$ & $\begin{array}{l}\text { Omission } \\
\text { error }\end{array}$ \\
\hline & fire & 353817 & 15631 & 369448 & $4 \%$ \\
\hline $\begin{array}{l}\text { LFDB } \\
\text { and } \\
\text { FireM3 }\end{array}$ & non-fire & 30949 & 54563 & 85512 & $36 \%$ \\
\hline & column total & 384766 & 70194 & \multirow[t]{2}{*}{454960} & \\
\hline & $\begin{array}{l}\text { commission } \\
\text { error }\end{array}$ & & & \\
\hline & $\begin{array}{l}\text { Overall accura } \\
\text { Kappa }\end{array}$ & \multicolumn{2}{|c|}{$=89.76 \%$} & & \\
\hline
\end{tabular}

There is a tendency for the older scars of 1981 to show lower probability values (the 1981 and 1989 scars have an average probability of 0.44 and 0.68 respectively). This is not surprising, since the NDSWIR values for 1981 fire scars showed a high degree of overlap with the NDSWIR values of non-burned forested areas. The fire scars created in 1989 and later are clearly visible on the probability map. Comparison with the LFDB fire map gives a correspondence of 89\%, 69\% and 69\% for fire scars of 1989, 1991 and 1992 (Table III). This confirms that the method can detect fire scars that were created 10 years prior to the acquisition date of the imagery used.

TABLE III

Correspondence between the fire probability map and LFDB fires scars created in single years.

\begin{tabular}{|c|c|c|c|}
\hline Year & $\begin{array}{l}\text { LFDB } \\
\text { Area } \\
(\mathrm{km} 2)\end{array}$ & \multicolumn{2}{|c|}{$\begin{array}{l}\text { Areas with }>50 \% \text { fir } \\
\text { scar probability } \\
\text { Area corresponding } \\
\text { with LFDB }\end{array}$} \\
\hline 1980 & 3408 & 1873 & 55 \\
\hline 1981 & 6965 & 5020 & 72 \\
\hline 1983 & 6 & 0 & 0 \\
\hline 1984 & 113 & 30 & 27 \\
\hline 1987 & 1152 & 867 & 75 \\
\hline 1988 & 366 & 181 & 49 \\
\hline 1989 & 39052 & 34721 & 89 \\
\hline 1991 & 281 & 193 & 69 \\
\hline 1992 & 1874 & 1290 & 69 \\
\hline
\end{tabular}

Just as fires mapped in LFDB as a single-event are often associated with multiple segments, the probability map shows different degrees of probability within fire scars. In addition, probabilities may vary between fire scars of the same age (for two individual fire scars of 1989 the average probability was 0.86 and 0.68). NDSWIR values in fire scars converge towards those found in 'undisturbed' forest as the vegetation regenerates and this results in lower estimates of fire scar probability. These differences in probability within singleevent fire scars and between fire scars of the same age could point to differences in fire severity or re-growth and need further investigation.

2) Fire probability map for the full study area

The full study area is more likely to include fire scars of all ages and various degrees of recovery and, when examining the NDSWIR histogram for the full study area we found no bimodal distribution (Fig. 8 top). Nevertheless, we implemented the a posteriori labeling procedure and produced a fire scar probability map (Fig. 8 bottom) from the six segmented SPOT VEGETATION images which exhibited the lowest overall cloud cover and haze. Although the histograms extracted for all six images were uni-modal the resulting probability map compares well with the probability map produced by means of threshold values based on the subset area (e.g. when thresholding a single SPOT VEGETATION image $33.6 \%$ of the pixels in the subset area were identified as fire scar by a full area threshold compared to $28.3 \%$ by a subset area threshold).

Outside the subset area, the probability map shows two areas of high probability where the occurrence of fire is doubtful. The first is an area in the north east, bordering the Hudson Bay and the second is in the north west of the image. These areas are relatively large and, according to the IGBP global land cover map, the main vegetation is 'closed shrubland' or 'woody savannas'. Young regenerating fire scars will consist of small trees and other low growing vegetation such as ferns and shrubs and may result in NDSWIR values typical of shrubland communities.

\section{DISCUSSION}

The results showed how the NDSWIR and shortwaveinfrared waveband can clearly differentiate between fire scars of up to 10 years old and the other patches in the boreal landscape. Both approaches were superior to the use of either other SPOT-VEGETATION wavebands or NDVI. The results also demonstrated how the segmentation of multi-temporal NDSWIR images can be used to produce a fire scar probability map. So, in principle, it should be possible to map older regenerating fire scars in the boreal forest at continental scale in an operational manner using NDSWIR based on shortwave-infrared reflectance data. Nevertheless, there are limitations and problems related to our method.

The optimisation of the input parameters of the segmentation procedure relies on some prior knowledge of the fire scar size distribution for the area. If this is not available it may be difficult to objectively identify optimal input parameters.

The application of an optimization using Student ' $t$ ' values to identify an adequate NDSWIR threshold performs well when the NDSWIR image histogram shows a clear bimodal distribution. Applying the method when the image histogram is uni-modal (as was the case for the full study site), is not strictly valid. There may be several factors that cause the 
NDSWIR histogram to be uni-modal. Because the area is so large, the relative proportion of pixels representing fire scars may be to small to have a significant effect on the histogram. The presence of different vegetation types and the variation in viewing angle may increase the variability of the NDSWIR beyond acceptable levels. One solution may be to compute firescar probability maps by applying thresholds specific to individual images and geographical areas. Sub-area histograms could be extracted on the basis of vegetation type, view angle range and a pre-defined maximum extent.

We were only able to validate the results on a relatively small area of the Canadian boreal forest. Although the probability map produced for the full extent of the Canadian boreal forests appeared to be consistent with expectations, the product needs further validation with independent information on fire scars outside the subset area.

NDSWIR is sensitive to canopy structure and moisture content. As a result, we anticipate confusion between vegetation types which have a similar structure to regenerating fire scars (e.g. shrubland). One solution may be to isolate the forested areas prior to implementing the procedure. However, this imposes superficial boundaries on the landscape which are not necessarily respected by fires.

Cloud cover is a major problem in the boreal zone and, although the proposed method can cope with some degree of cloud, it still relies on a minimum number of cloud-free overpasses within one season. Selecting a series of 'best' images showing a minimum amount of overall cloud cover is not automatically the right solution when dealing with a large continental area as cloud cover often tends to persist or recur over specific parts of the landscape. A much better approach would be to use a complete time-series of imagery (from spring to autumn) as a large number of layers will increase the reliability of the probability values and for cloudy areas increase the chance of cloud free coverage. Note that the reliability of the fire scar probability map is a per-pixel measure.

Finally, the spectral behaviour of fire scars in the Canadian boreal forest does not allow the reliable detection of fire scars created more than 10 years before image acquisition. In order to extend the temporal range of fire scar mapping the method depends upon past and future satellite data acquisitions in the NIR and SWIR spectrum. Current and past sensors which record in the NIR and SWIR are Landsat TM/ETM, ATSR-2, SPOT VEGETATION and AATSR. The TM sensor provides imagery going back to 1982 but the spatial resolution of $30 \mathrm{~m}$ means that extremely high data volumes would need to be processed to provide comprehensive cover of the boreal zone. The low repeat frequency (16 days) also reduces the chance of acquiring multiple cloud-free images for any one area in a single growth season. ATSR-2, SPOT VEGETATION and AATSR, on the other hand, have a coarse spatial resolution of $1 \mathrm{~km}$ and a high repeat frequency (1,3 days) but came into operation in 1995, 1998 and 2002 respectively, limiting potential backdating to the early 80 's. Moreover, their coarse spatial resolution restricts the mapping to fire scars of several $\mathrm{km}^{2}$ in size. In Siberia, these sensors would fail to spot about $50 \%$ of the fire scars (Shvidenko - personal communication).
A solution might be to combine fine scale but local fire scar information from TM with the coarse scale but global information from SPOT VEGETATION, ATSR-2 or AATSR. Medium scale $(500 \mathrm{~m})$ mapping of older fire scars using the SWIR would also be possible by means of MODIS imagery (from 2001)

\section{CONCLUSION}

Monitoring the spatial and temporal dynamics of forest fires is vital for assessing the impacts of global environmental change. Data from AVHRR, ATSR-2 and SPOTVEGETATION have been used for fire hotspot mapping and assessment of area burned in the same year as the imagery. To date, a number of national and global fire hotspot and recent fire scar products derived from Earth observation are available online, but tools for large area monitoring of older fire scars and their regeneration patterns are not well developed.

Examination of SPOT VEGETATION NDVI and NDSWIR (indices based on the Red - NIR and NIR - SWIR wavebands respectively) revealed a closer association of the NDSWIR with fire scars of varying age. A segmentation system using a time series of NDSWIR consisting of good quality images was developed which reliably differentiates older fire scars from unburnt forests. The method uses an objective optimisation of the segmentation parameters and an a posteriori assignment of fire scar segments through adaptive NDSWIR thresholding. The final product is a fire scar probability map. The method has been tested on a large area of the Canadian boreal forest. Further research will focus on ways of validating the fire scar probability maps and assess whether the NDSWIR of fire scars is related to fire scar age, intensity of the fire and rate of recovery of fire scars.

\section{ACKNOWLEDGMENT}

This work was funded by the Natural Environment Research Council (NERC). We wish to thank Brian Stocks, of the Canadian Fire Services (CFS) for the supply of Large Fire Data Base Bryan Lee and Robert Fraser (CFS) for access to FireM3 data, the Centre National d'Etudes Spatiales (CNES) for providing the SPOT-VEGETATION images through the Preparatory Programme Investigation and Tristan Quaife (University of Wales, Swansea) for access to the SMAC v2.0 software interface.

\section{REFERENCES}

Y. Malhi, D. D. Baldocchi, and P. G. Jarvis, "The carbon balance of tropical, temperate and boreal forests," Plant Cell and Environment, vol. 22, pp. 715740, 1999.

[2] E. D. Schulze, J. Lloyd, F. M. Kelliher, C. Wirth, C. Rebmann, B. Luhker, M. Mund, A. Knohl, I. M. Milyukova, W. Schulze, W. Ziegler, A. B. Varlagin, A. F. Sogachev, R. Valentini, S. Dore, S. Grigoriev, O. Kolle, M. I. Panfyorov, N. Tchebakova, and N. N. Vygodskaya, "Productivity of forests in the Eurosiberian boreal region and their potential to act as 
a carbon sink - a synthesis," Global Change Biology, vol. 5, pp. 703-722, 1999.

[3] M. L. Goulden, S. C. Wofsy, J. W. Harden, S. E. Trumbore, P. M. Crill, S. T. Gower, T. Fries, B. C. Daube, S. M. Fan, D. J. Sutton, A. Bazzaz, and J. W. Munger, "Sensitivity of boreal forest carbon balance to soil thaw," Science, vol. 279, pp. 214-217, 1998.

[4] W. R. Cofer, J. S. Levine, E. L. Winstead, D. R. Cahoon, D. I. Sebacher, J. P. Pinto, and B. J. Stocks, "Source compositions of trace gases released during African savanna fires," Journal of Geophysical Research-Atmospheres, vol. 101, pp. 23597-23602, 1996.

[5] E. S. Kasischke, K. Bergen, R. Fennimore, F. Sotelo, G. Stephens, A. Janetos, and H. H. Shigart, "Satellite imagery gives clear picture of Russia's boreal forest fire," EOS Trans American Geophys Union, vol. 80, pp. 141-147, 1999.

[6] E. A. Johnson and S. L. Gutsell, "Heat-Budget and Fire Behavior Associated With the Opening of Serotinous Cones in 2 Pinus Species," Journal of Vegetation Science, vol. 4, pp. 745-750, 1993.

[7] S. Payette, "The Range Limit of Boreal Tree Species in Quebec-Labrador - an Ecological and Paleoecological Interpretation," Review of Palaeobotany and Palynology, vol. 79, pp. 7-30, 1993.

[8] A. Z. Shvidenko, S. Nilsson, V. S. Stolbovoi, M. Gluck, D. G. Shchepashchenko, and V. A. Rozhkov, "Aggregated estimation of the basic parameters of biological production and the carbon budget of Russian terrestrial ecosystems: 1 . Stocks of plant organic mass," Russian Journal of Ecology, vol. 31, pp. 371-378, 2000.

[9] B. J. Stocks, M. A. Fosberg, T. J. Lynham, L. Mearns, B. M. Wotton, Q. Yang, J. Z. Jin, K. Lawrence, G. R. Hartley, J. A. Mason, and D. W. McKenney, "Climate change and forest fire potential in Russian and Canadian boreal forests," Climatic Change, vol. 38, pp. 1-13, 1998.

[10] I. Piccolini, "Adaptive algorithm for global automatic burnt surfaces estimation with ATSR-2 data, Algorithm Technical Background Document," European Space Agency 2000.

[11] J. Liu, J. M. Chen, J. Cihlar, and W. M. Park, "A process-based boreal ecosystem productivity simulator using remote sensing inputs," Remote Sensing Environment, vol. 62, pp. 158-175, 1997.

[12] A. Shvidenko and S. Nilsson, "Extent, distribution, and ecological role of fire in Russian forests," in Fire, Climate Change and Carbon Cycling in the Boreal Forest, E. Kasischke and B. Stocks, Eds. Berlin, Germany: Springer-Verlag, 2000.

[13] Z. Li, J. Cihlar, L. Moreau, F. Huang, and B. Lee, "Monitoring fire activities in the boreal ecosystem," Journal of Geophysical Research, vol. 102, pp. 2961129624, 1997.
[14] Z. Li, S. Nadon, J. Cihlar, and B. Stocks, "Satellitebased mapping of Canadian boreal forest fires: evaluation and comparison of algorithms," International Journal of Remote Sensing, vol. 21, pp. 3071-3082, 2000.

[15] D. R. Cahoon, B. J. Stocks, J. S. Levine, W. R. Cofer, and C. C. Chung, "Evaluation of a Technique For Satellite-Derived Area Estimation of Forest-Fires," Journal of Geophysical Research-Atmospheres, vol. 97, pp. 3805-3814, 1992.

[16] E. S. Kasischke, N. H. F. French, P. Harrell, N. L. Christensen, S. L. Ustin, and D. Barry, "Monitoring of Wildfires in Boreal Forests Using Large-Area Avhrr Ndvi Composite Image Data," Remote Sensing of Environment, vol. 45, pp. 61-71, 1993.

[17] P. M. Barbosa, J. M. Gregoire, and J. M. C. Pereira, "An algorithm for extracting burned areas from time series of AVHRR GAC data applied at a continental scale," Remote Sensing of Environment, vol. 69, pp. 253-263, 1999.

[18] R. H. Fraser, Z. Li, and J. Cihlar, "Hotspot and NDVI differencing synergy (HANDS): A new technique for burned area mapping over boreal forest," Remote Sensing of Environment, vol. 74, pp. 362-376, 2000.

[19] K. R. Al-Rawi, J. L. Casanova, and A. Romo, "IFEMS: a new approach for monitoring wildfire evolution with NOAA-AVHRR imagery," International Journal of Remote Sensing, vol. 22, pp. 2033-2042, 2001.

[20] O. Arino, I. Piccolini, E. Kasischke, F. Siegert, E. Chuvieco, P. Martin, Z. Li, R. Fraser, H. Eva, D. Stroppiana, J. Pereira, J. M. N. Silva, D. Roy, and P. Barbosa, "Burn scar mapping methods.," Submitted to GOFC Special Issue of Remote Sensing of Environment, December 1999, 1999.

[21] Y. J. Kaufman, C. O. Justice, L. P. Flynn, J. D. Kendall, E. M. Prins, L. Giglio, D. E. Ward, W. P. Menzel, and A. W. Setzer, "Potential global fire monitoring from EOS-MODIS," Journal of Geophysical Research-Atmospheres, vol. 103, pp. 32215-32238, 1998.

[22] H. Eva and E. F. Lambin, "Burnt area mapping in Central Africa using ATSR data," International Journal of Remote Sensing, vol. 19, pp. 3473-3497, 1998.

[23] I. Piccolini and O. Arino, "An adaptive algorithm for automatic burned surfaces estimation with ERS-2 ATSR-2 data.," Submitted to International journal of Remote Sensing, August 1999, Submitted.

[24] R. H. Fraser, Z. Li, and R. Landry, "SPOT VEGETATION for characterizing boreal forest fires," International Journal of Remote Sensing, vol. 21, pp. 3525-3532, 2000.

[25] M. C. Pereira and A. W. Setzer, "Spectral Characteristics of Fire Scars in Landsat-5 Tm Images of Amazonia," International Journal of Remote Sensing, vol. 14, pp. 2061-2078, 1993. 
[26] H. Epp and R. A. Lanoville, "Satellite data and geographic information systems for fire and responce management in the Cannadian Arctic," Geocarto International, vol. 11, pp. 97-104, 1996.

[27] J. Rogan and S. R. Yool, "Mapping fire-induced vegetation depletion in the Peloncillo Mountains, Arizona and New Mexico," International Journal of Remote Sensing, vol. 22, pp. 3101-3121, 2001.

[28] F. Siegert and A. A. Hoffman, "The 1998 forest fires in East Kalimantan (Indonesia): a quantitative evaluation using high resolution, multitemporal ERS-2 SAR images and NOAA-AVHRR hotspot data," Remote Sensing of Environment, vol. 72, pp. 64-77, 2000.

[29] V. Cuomo, R. Lasaponara, and V. Tramutoli, "Evaluation of a new satellite-based method for forest fire detection," International Journal of Remote Sensing, vol. 22, pp. 1799-1826, 2001.

[30] E. S. Kasischke and N. H. F. French, "Locating and Estimating the Areal Extent of Wildfires in Alaskan Boreal Forests Using Multiple-Season AVHRR NDVI Composite Data," Remote Sensing of Environment, vol. 51, pp. 263-275, 1995.

[31] J. A. Eastwood, S. E. Plummer, B. K. Wyatt, and B. J. Stocks, "The potential of SPOT-Vegetation data for fire scar detection in boreal forests," International Journal of Remote Sensing, vol. 19, pp. 3681-3687, 1998.

[32] J. M. C. Pereira, "A comparative evaluation of NOAA/AVHRR vegetation indexes for burned surface detection and mapping," Ieee Transactions On Geoscience and Remote Sensing, vol. 37, pp. 217-226, 1999.

[33] H. Eva and E. F. Lambin, "Burnt Area Mapping in Central Africa using ATSR data," International Journal of Remote Sensing, vol. 19, pp. pp. 34733497, 1998.

[34] L. T. Steyaert, F. G. Hall, and T. R. Loveland, "Land cover mapping, fire regeneration, and scaling studies in the Canadian boreal forest with $1 \mathrm{~km}$ AVHRR and Landsat TM data," Journal of Geophysical Research, vol. 102, pp. 29581-29598, 1997.

[35] O. Arino and I. Piccolini, "Development and testing of algorithms for a global burnt area product from ERS ATSR-2," presented at IGARSS-2000, 2000.

[36] Z. Li, R. Fraser, and A. Khananian, "Remote sensing of forest fires in boreal ecosystem from space," in Remote Sensing For Earth Science, Ocean, and Sea Ice Applications, vol. 3868, Proceedings of the Society of Photo-Optical Instrumentation Engineers (Spie), 1999, pp. 228-231.

[37] H. Rahman and G. Dedieu, "SMAC: a simplified method for the atmospheric correction of satellite measurements in the solar spectrum," Int. J. REmote Sensing, vol. 15, pp. 123-143, 1994.

[38] R. Cook, I. McConnell, and C. Oliver, "Mum (Merge Using Moments) Segmentation for Sar Images," in Sar Data Processing for Remote Sensing, vol. 2316,
Proceedings of the Society of Photo-Optical Instrumentation Engineers (Spie), 1994, pp. 92-103.

[39] S. Plummer, F. Gerard, L. Lliffe, and B. Wyatt, "Fire Scar Detection in the Canadian Boreal Forest," in Proceedings of VEGETATION 2000 conference, Belgirate, Italy, 2000, CDROM. http://vegetation.cnes.fr/vgtprep/vgt2000/plummer.html 


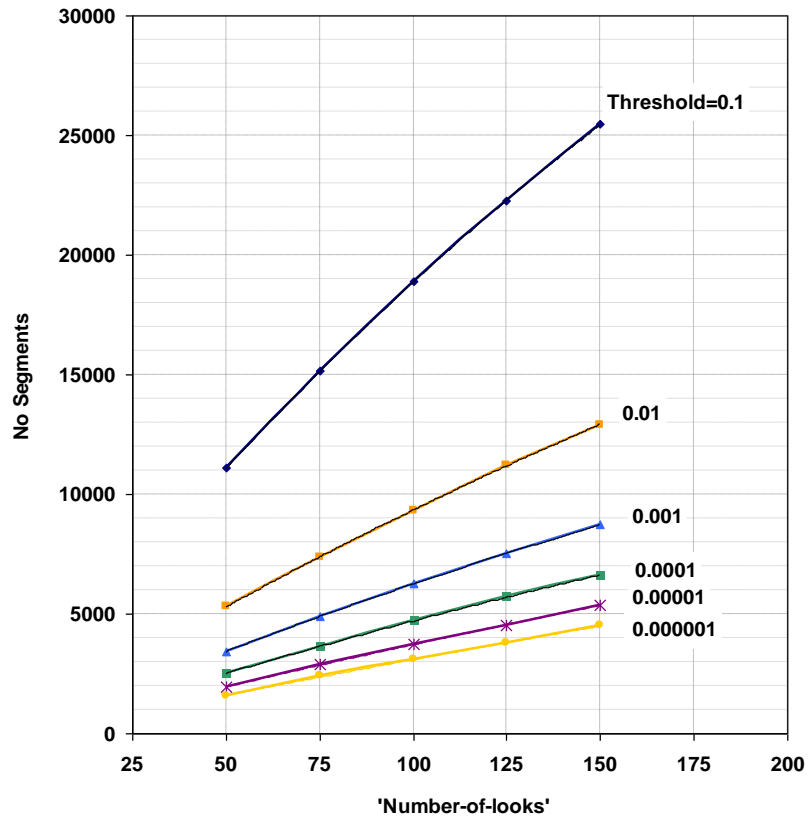

Fig. 1. Variation in number of segments produced from a $700 \mathrm{~km} \mathrm{x}$ $700 \mathrm{~km}$ NDSWIR SPOT VEGETATION image by the ERDAS CAESAR MUM image segmentation procedure as a function of the input parameters 'threshold' and 'number-of looks'.
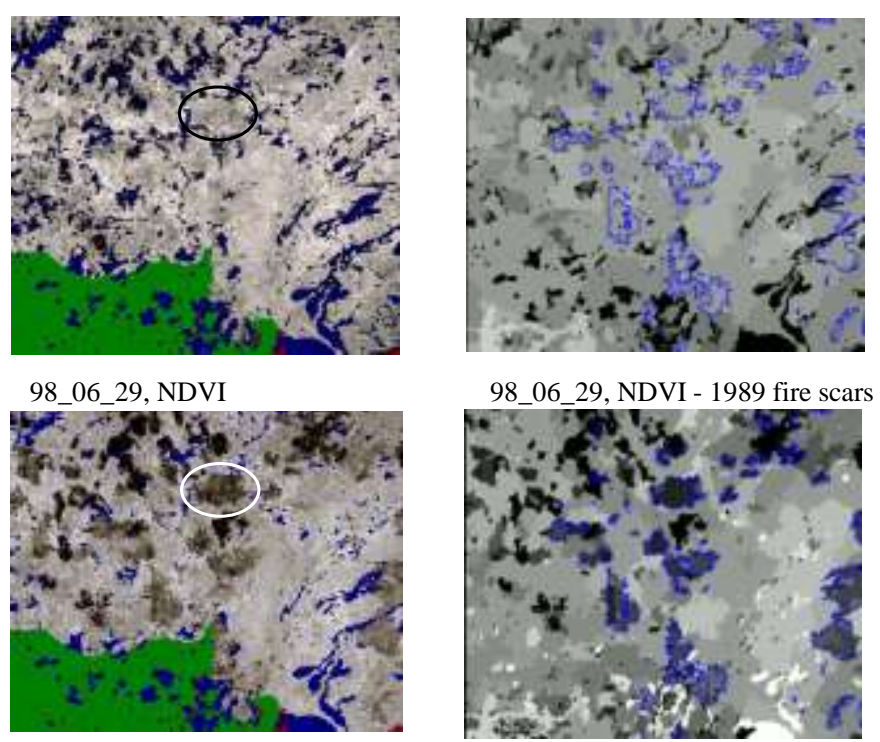

98_06_29, NDVI - 1989 fire scars

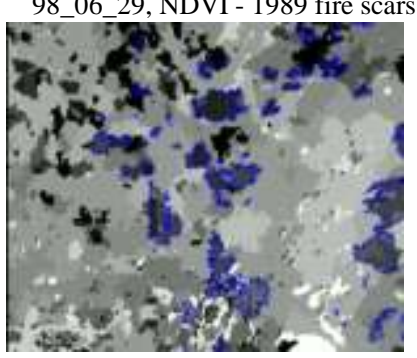

98_06_29, NDSWIR

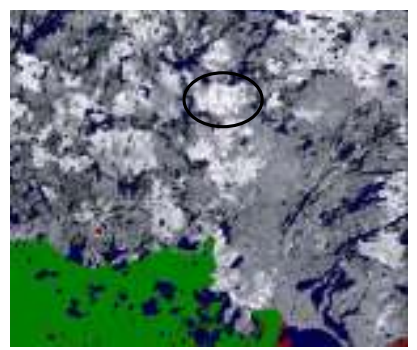

98_06_29, SWIR
98_06_29, SWIR - 1989 fire scars

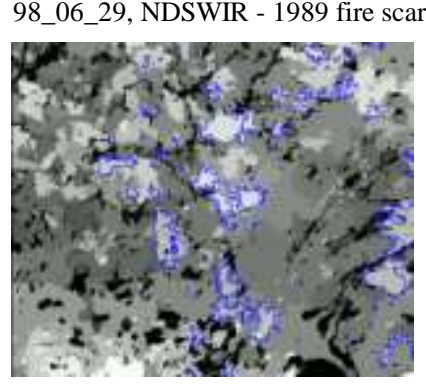

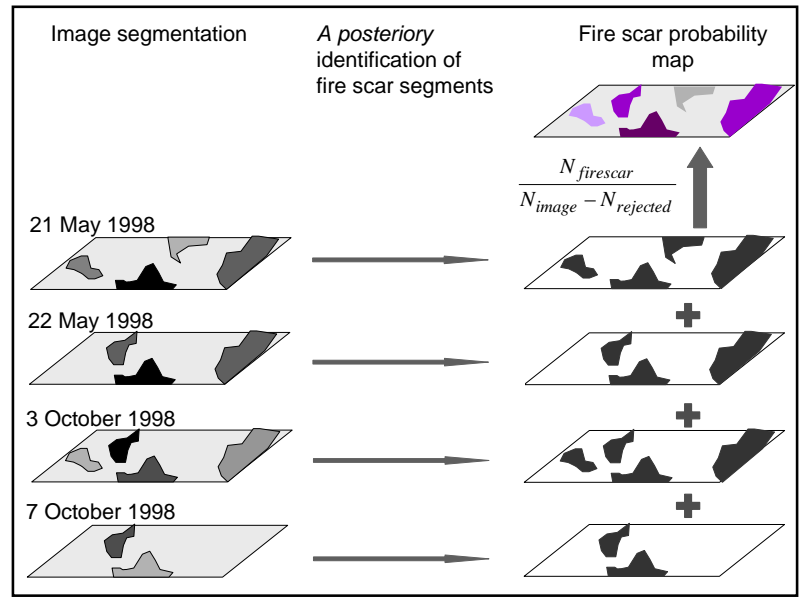

Fig.2. Schematic outline of the method used to produce fire scar probability maps by combining NDSWIR SPOT VEGETATION image segmentations from multiple dates of a single year (1998).

Fig. 3. NDVI, NDSWIR, SWIR and respective segmentations for June 29th 1998 compared with the LFDB fire scar polygons of 1989. The smooth dark grey areas in the bottom left hand corner of the plates on the left represent masks for arable land. The black areas represent water. 
22 May 1998

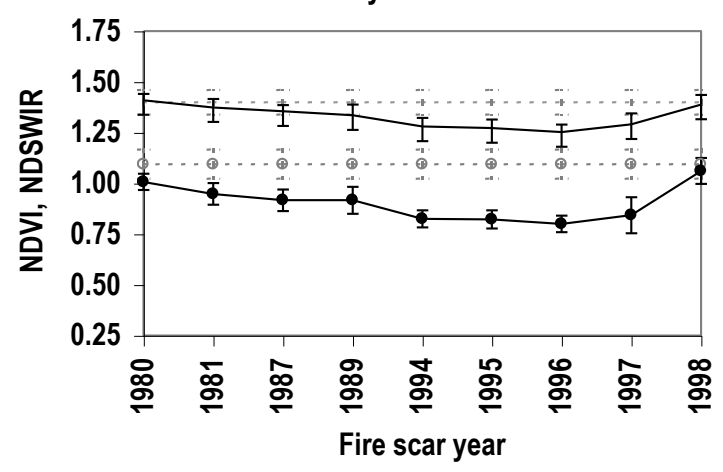

29 June 1998

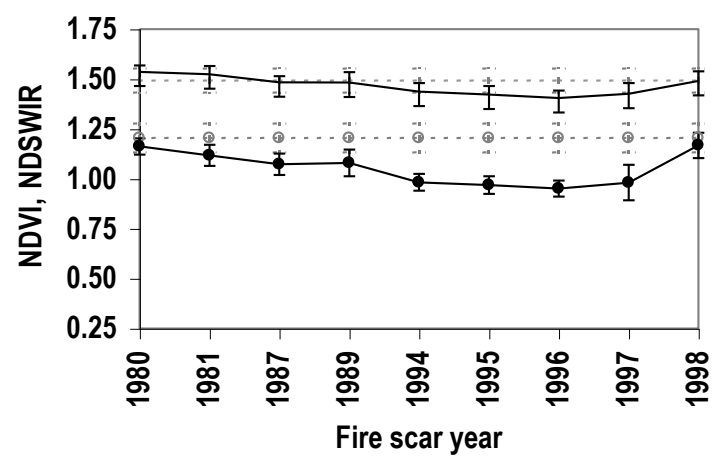

3 Oct 1998

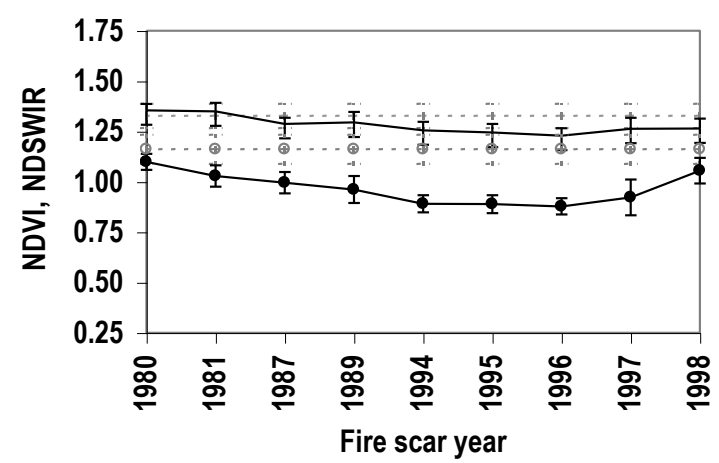

...... NDVI, unburnt $\quad$ NDVI, burnt

...... NDSWIR, unburnt $\longrightarrow$ NDSWIR, burnt

Fig. 4. Behaviour of NDVI and NDSWIR with fire scar age as seen from SPOT VEGETATION imagery of May 22nd 1998 (top), June 29th 1998 (middle) and October 3rd 1998 (bottom). The dotted line represents the corresponding VI value for the surrounding 'unburned' forest. Both VIs are scaled positive for averaging.
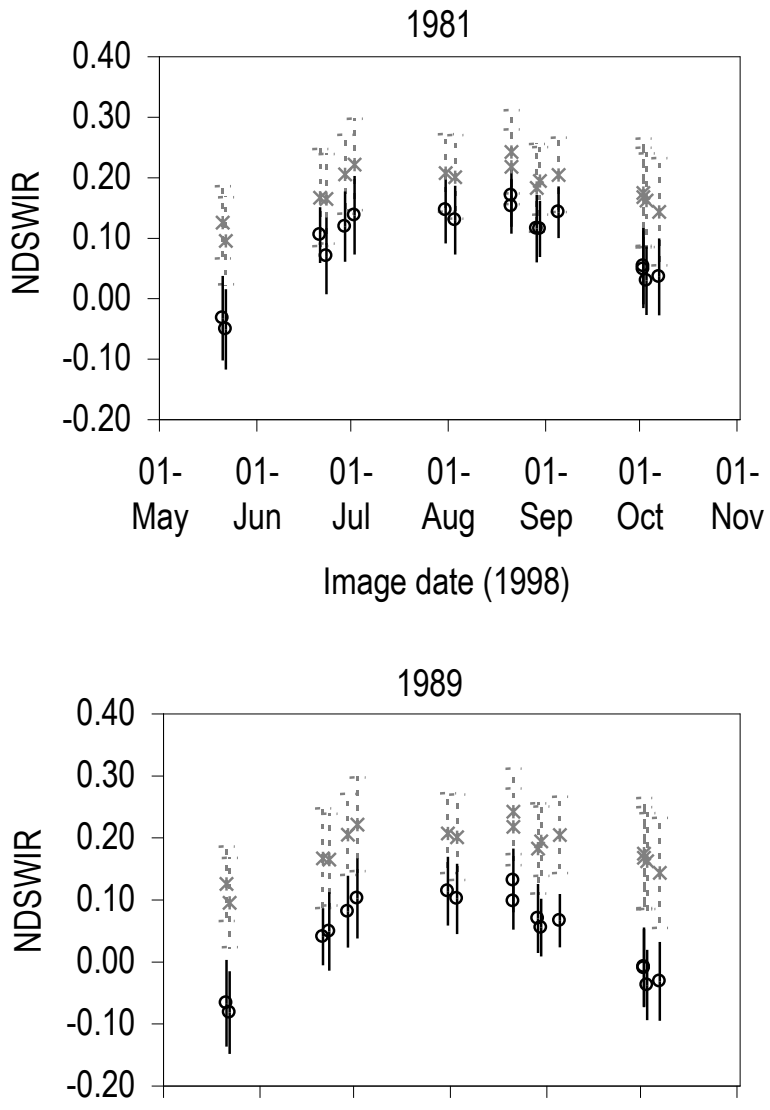

01- 01- 01- 01- 01- 01- 01May Jun Jul Aug Sep Oct Nov Image date (1998)

* Forest canopy o Fire scar

Fig. 5. Comparing the seasonal behaviour of NDSWIR of fire scars created in 1981 (top) and 1989 (bottom) with the surrounding unburnt forest. 

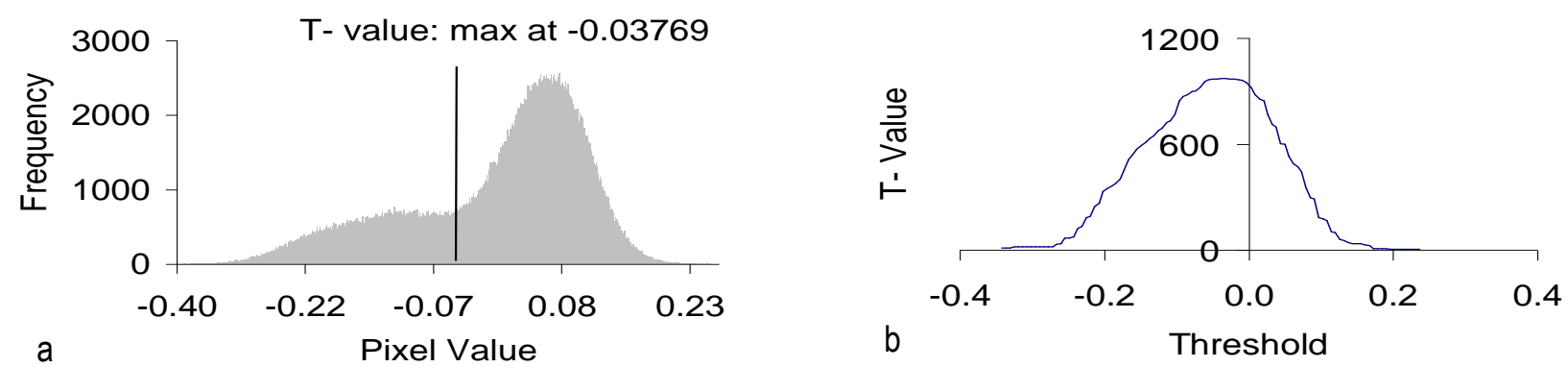

Fig. 6. NDSWIR histogram from a 700km x 700km subset area of a single SPOT-VEGETATION image with optimal threshold value (a) identified by maximising the Student $-\mathrm{t}$ value (b).
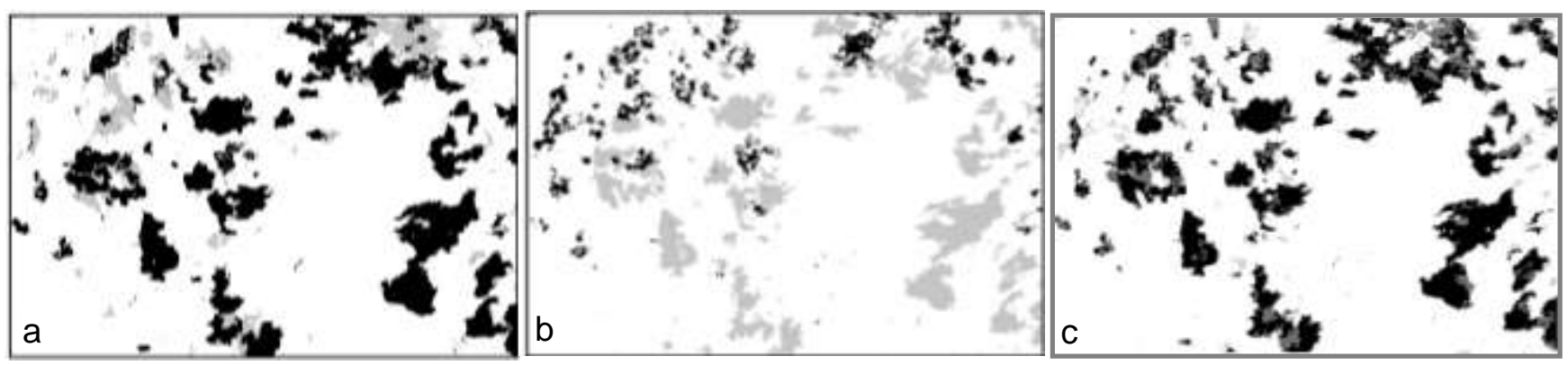

Fig. 7. Fire scar probability map for subset area created from 17 multi-temporal SPOT VEGETATION images; white: probability <50\%; grey: probability 50\%-75\%; black: probability > 75\% (a). The LFDB (1980-1994) fire scar polygon map of the Canadian Forest Services in grey and the FireM3 (1995-1998) hotspot data of CCRS (Canada) in black (b). The correspondence between fire probability >=50\% and the LFDB polygon map and FireM3 hotspot data; black and white: a match; dark grey: error of commission; light grey error of omission (c).
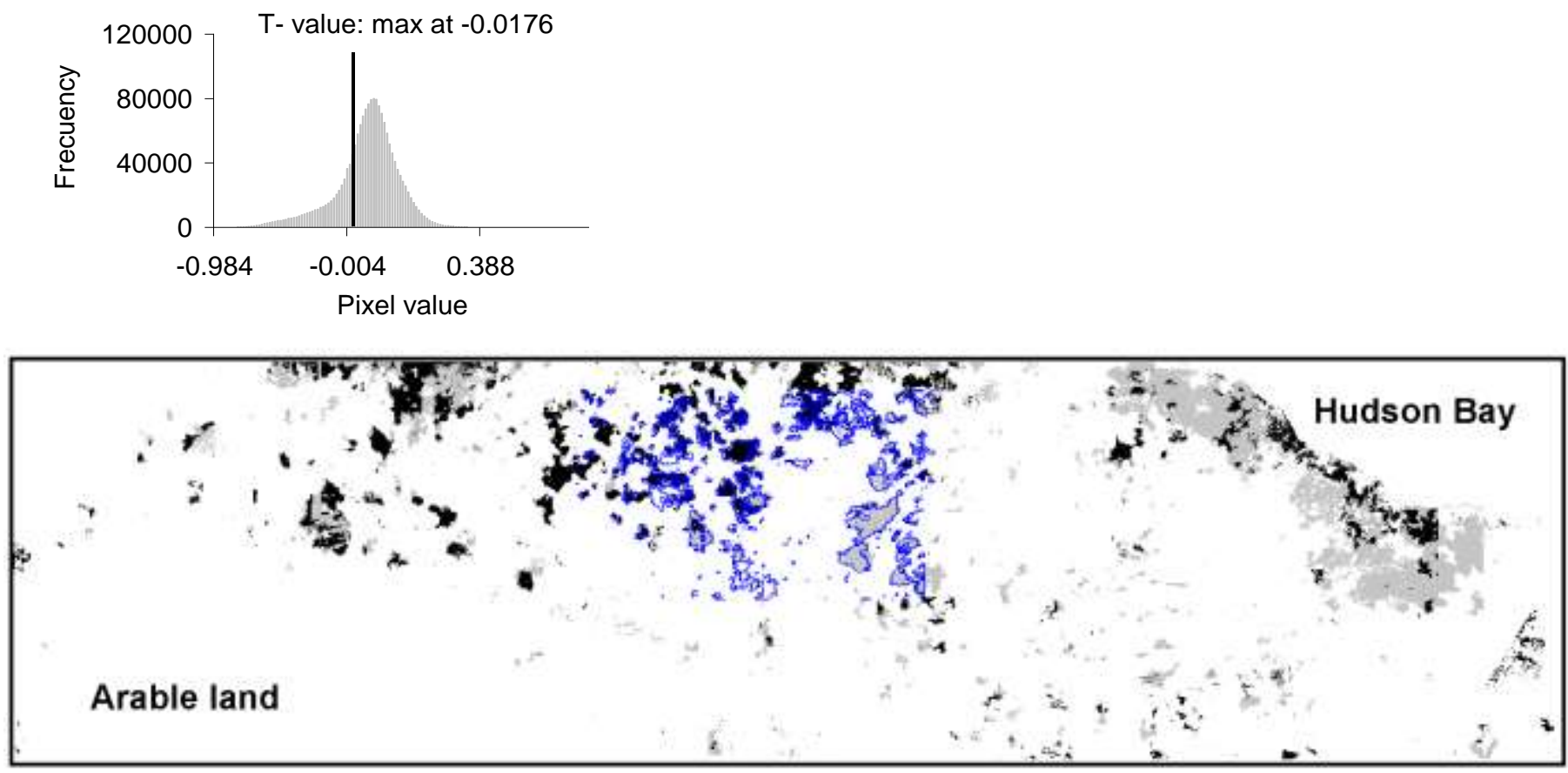

Fig. 8. NDSWIR histogram of a single SPOT-VEGETATION image covering the full study area with optimal threshold value (top) and resulting fire scar probability map based on six 'best' (i.e. least cloud) SPOT VEGETATION images (bottom). 